\title{
Forecast model for estimating the service life of a diagnosed object based on the Neyman- Pearson method
}

\author{
Sergey Barsukov ${ }^{1, *}$, and Sergey Pakhomov ${ }^{1}$ \\ ${ }^{1}$ Irkutsk State Transport University, 664074 Irkutsk, Russia
}

\begin{abstract}
The paper is aimed at developing a forecast model for estimating the service life of a diagnosed object based on the NeymanPearson method. It presents a procedure for selecting necessary and sufficient number of diagnostic indicators using the forecast model. The technique has been tested on the basis of a power transformer with a liquid dielectric. A condition-based operation strategy has been proposed for the transformer. According to this strategy, the iron impurity content in the dielectric liquid (oil) of the transformer should be measured every year of operation. Based on the forecast model, it is possible to calculate the variation of average risk $(R)$ and a threshold value of iron impurity content in the transformer oil $\left(k_{0}\right)$ for each year of operation. Using these parameters, a reliable forecast model can be constructed to estimate the remaining service life of the transformer. The obtained relationships make it possible to identify a scientifically grounded stage in the service life of a diagnosed object, at which the number of measurable diagnostic indicators (indicators that are necessary for assessing the real technical condition of equipment) can be minimized.
\end{abstract}

\section{Introduction}

At present, two traditional approaches to preventive maintenance of equipment are used [14]: the scheduled maintenance system (service life-based maintenance) and maintenance according to the current technical condition (condition-based maintenance). The key difference between these approaches is in different grounds for determining the frequency and scope of maintenance for a diagnosed object. There is a clear trend towards introducing the principle of condition-based maintenance for different units, assemblies and structural elements. For this purpose, numerous studies and experiments are carried out to expand a range of systems and assemblies operated under this strategy.

The primary objective of the transition to the condition-based maintenance strategy [1$5]$ is to improve the reliability of equipment and reduce maintenance costs. The implementation of the condition-based maintenance strategy requires a sufficient number of informative diagnostic indicators to assess the real technical condition of a diagnosed object and predict its operability.

\footnotetext{
*Corresponding author: bars_irkutsk@mail.ru
} 
The operating time of any system, as well as the scope and frequency of preventive maintenance work is determined by threshold values of monitored parameters (diagnostic indicators) [6]. In order to reliably diagnose the technical condition of a system, the maximum amount of information about monitored parameters should be used. This diagnostic method minimizes the probability of a wrong decision. However, the related monitoring systems would be overloaded with sensors, while diagnostic programs would be very cumbersome and time-consuming. This reduces the economic efficiency of equipment. In this regard, it is important to take a science-based approach by identifying diagnostic indicators and then selecting, among them, the minimum number of indicators that are necessary and sufficient to reliably diagnose the technical condition of a system (remaining service life). In this case, both a diagnosed object and monitoring facilities will be as simple and effective as possible.

Therefore, the studies in which forecast models are constructed to estimate the remaining service life of a diagnosed object are of current interest [7-11]. In addition, there is a need for methods that make it possible to reduce the number of measured parameters, which are necessary and sufficient to reliably diagnose a monitored system [12].

The purpose of this study is to develop a tool (procedure) that can be used to reliably assess the current condition of a monitored object. Based on a reliable diagnosis of the technical condition, it is possible to introduce a condition-based preventive maintenance strategy.

The novelty of the study is in presenting the forecast model that, unlike the existing forecast models, is designed to estimate the remaining service life of a diagnosed object by year of operation. The forecast model is based on the Neyman-Pearson method. It also focuses on estimating how the average risk of a wrong decision concerning the technical condition of a diagnosed object varies from year to year.

\section{Research methods}

There are statistical methods that can be used to recognize indicators $[1-3,13-15]$ and, therefore, set limits to making a decision about the technical condition of a diagnosed object. In addition, these methods allow possible diagnostic errors to be quantified. Danger of a wrong diagnostic decision is quantified through average risk assessment. For this purpose, it is necessary to determine a probability density of a particular diagnostic parameter $k$, which is used to identify whether a diagnosed object is serviceable $\left(D_{1}\right)$ or unserviceable $\left(D_{2}\right)$.

Let us introduce the following notations:

$k$ is the output performance parameter of a diagnosed object;

$k_{0}$ is the threshold value of the output performance parameter.

The parameter $k_{0}$ indicates a degree of serviceability of equipment:

- at $k<k_{0} \quad k \in D_{1}$, a diagnosed object is serviceable;

- at $k>k_{0} \quad k \in D_{2}$, a diagnosed object is unserviceable (defective).

Thus, these inequalities are a quantitative measure of the remaining service life of a diagnosed object. Figure 1 shows values of the probability density of a diagnostic parameter $k$ for two statuses of a diagnosed object. In real systems, the probability densities $f\left(k / D_{1}\right)$ and $f\left(k / D_{2}\right)$ usually have a common area. Selecting a threshold value $k_{0}$ is subject to a certain risk that the current technical condition will be misdiagnosed. 


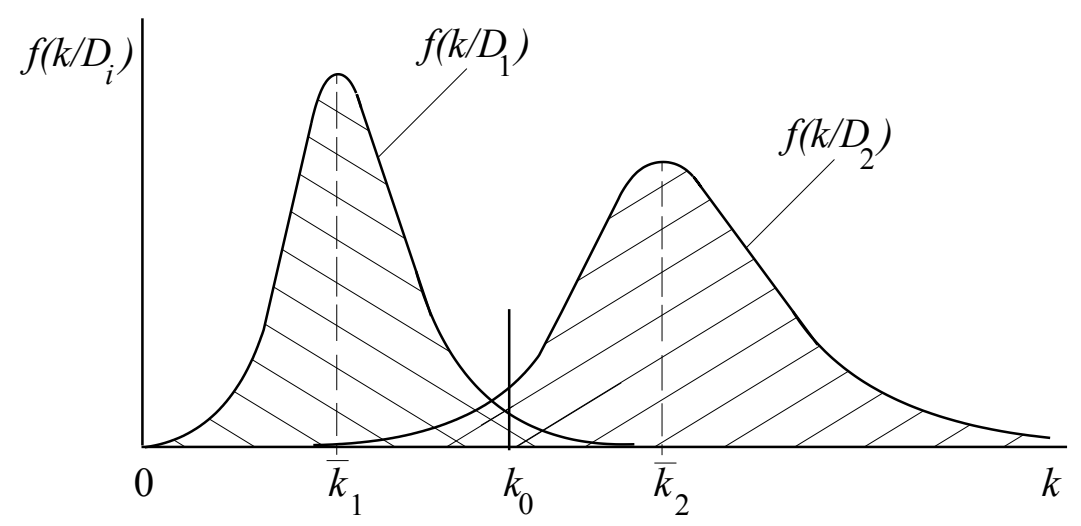

Fig. 1. Probability density of the diagnostic indicator $k$ for two statuses of a diagnosed object. $\bar{k}_{1}$ and $\bar{k}_{2}$ are the average values (mathematical expectations) of the diagnostic indicator $k$.

A wrong diagnostic decision (magnitude of the average risk) is defined as a sum of probable events:

$$
R=C_{21} \cdot P\left(H_{21}\right) \cdot \int_{k 0}^{\infty} f\left(k / D_{1}\right) \cdot d k+C_{12} \cdot P\left(H_{12}\right) \cdot \int_{-\infty}^{k 0} f\left(k / D_{2}\right) \cdot d k,
$$

where $P\left(H_{21}\right)$ is the probability of a false alarm; a serviceable diagnosed object is recognized as defective: a diagnosed object is serviceable (real condition of a diagnosed object $\left.-D_{1}\right)$, but the parameter $k$ exceeds its threshold value $\left(k>k_{0}\right)$;

$P\left(H_{12}\right)$ is the probability of a missed defect; a defective diagnosed object is recognized as serviceable (real condition of a diagnosed object $-D_{2}$ ), but the parameter $k$ is less than its threshold value $\left(k<k_{0}\right)$;

$C_{21}$ is the cost of a false alarm; $C_{12}$ is the cost of a missed defect.

Based on the Neyman-Pearson method, the probability of a missed defect will be minimized at a specified allowable level of false alarm probability.

\section{Results}

The method for selecting the necessary and sufficient number of diagnostic indicators based on the Neyman-Pearson method was tested on the basis of a power transformer with a liquid dielectric. A conventional maintenance procedure of the power transformer is based on preventive maintenance (service life-based operation).

The condition of the transformer is assessed by measuring the iron impurity content in its dielectric liquid (oil) (parameter $k$ ):

- if $k<k_{0}, k \in D_{1}$ (the transformer is recognized as serviceable);

- if $k>k_{0}, k \in D_{2}$ (the transformer is recognized as unserviceable).

In this case, $k_{0}$ is the threshold value of the iron impurity content in the transformer oil. According to the maintenance schedule, the diagnostics of the transformer is carried out every five years of operation on the basis of the iron impurity content in the transformer oil. In order to implement the condition-based maintenance strategy of the transformer, it is proposed to measure the iron impurity content in the tank oil every five years of operation, 
rather than every year.

Figure 2 shows the calculated probability density of the diagnostic parameter $k$ by year of operation with serviceable $D_{1}$ and unserviceable $D_{2}$ conditions of the transformer. The figure also shows a distribution of the threshold parameter $k_{0}$, which allows the remaining service life of the transformer to be assessed in real time.

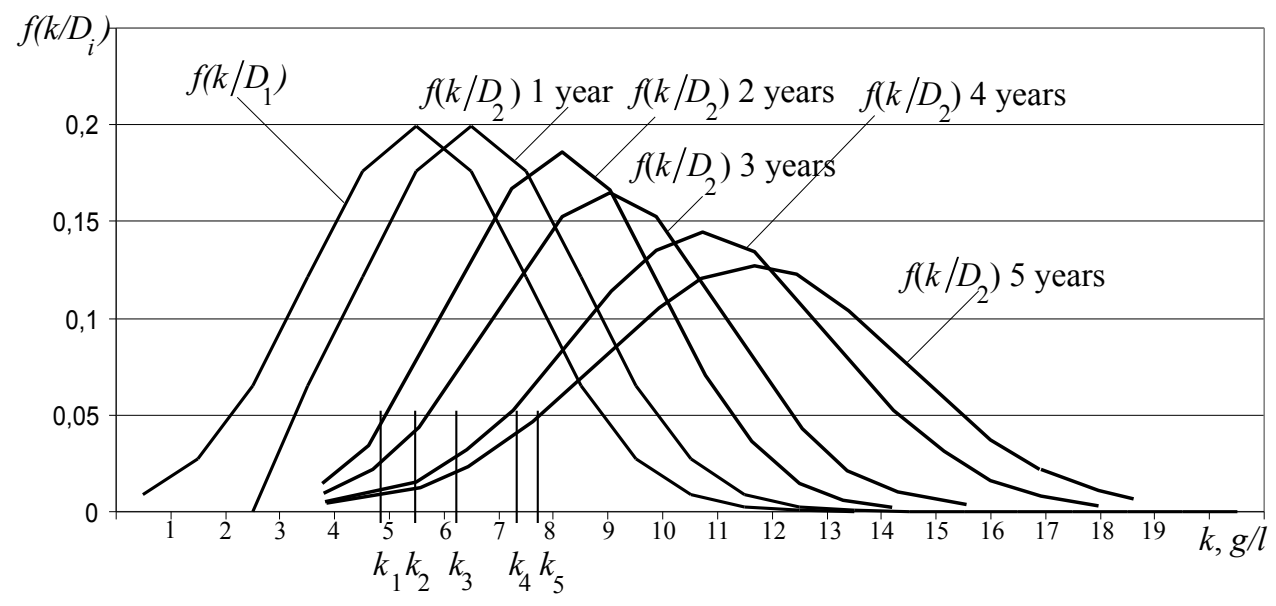

Fig. 2. Variation of the probability density of the diagnostic parameter $k$ by year of operation of the transformer, $k_{1}, \ldots, k_{5}$ is the distribution of the threshold parameter $k_{0}$ by year of operation of the transformer.

Figure 3 presents the variation of the false alarm and missed defect probabilities calculated on the basis of the Neyman-Pearson method, as well as the magnitude of the average risk by year of operation. The obtained characteristics make it possible to construct a reliable forecast model for estimating the remaining service life of a diagnosed object by varying the threshold parameter $k_{0}$. By estimating a threshold value of the average risk $R_{\max }^{\text {add }}$ of a wrong decision concerning the technical condition of the transformer, it is possible to identify a scientifically grounded stage in the service life of a diagnosed object, at which the number of measurable diagnostic indicators (indicators that are necessary for assessing the real technical condition of equipment) can be minimized.

The calculations performed for the diagnosed object demonstrate that, starting from the second year of operation, the risk of a wrong decision concerning the condition of the transformer decreases to an acceptable value. Quantitatively, this is justified by the fact that, starting from the second year of operation, the average risk $R$ falls below the accepted threshold value $R_{\max }^{a d d}=0.6$. By reducing the probability of a wrong decision concerning the condition of the transformer to the acceptable value, it is possible to reduce the number of measurable diagnostic indicators, without detriment to a reliable diagnosis of its technical condition. 


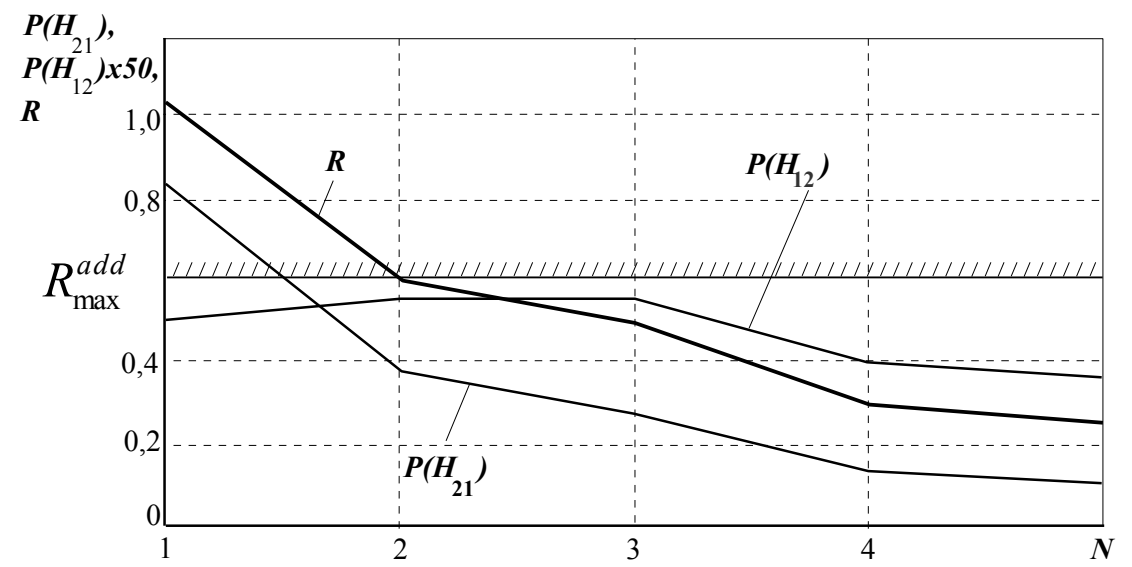

Fig. 3. Variation of the false alarm probability $P\left(H_{21}\right)$, probability of a missed defect $P\left(H_{12}\right)$ and average risk $R$ by year of operation $(N)$ of the power transformer.

\section{Conclusion}

The forecast model for estimating the service life of a diagnosed object has been constructed on the basis of the Neyman-Pearson method. The developed model can be used to introduce a condition-based preventive maintenance strategy. Based on the forecast model, the variation of the average risk of a wrong decision concerning the technical condition of the transformer $R$ has been calculated by year of operation. By comparing the average risk $R$ with the estimated threshold level of risk, $R_{\max }^{a d d}$ it is possible to identify a scientifically grounded stage in the service life of a diagnosed object, at which the number of measurable diagnostic indicators (indicators that are necessary for assessing the real technical condition of equipment) can be minimized.

\section{References:}

1. V.S. Malkin, Tehnicheskaja diagnostika. Uchebnoe posobie [Technical diagnostics. Textbook] (Lan' Publ., Moscow, 2013). (in Russian)

2. A.M. Safarbaklov, A.V. Lukyanov, S.V. Pakhomov, Osnovy tehnicheskoj diagnostiki detalej $i$ oborudovanija. Uchebnoe posobie. Ch.1 [Fundamentals of technical diagnostics of parts and equipment. Textbook, part 1] (Irkutsk State Transport University Publ., Irkutsk, 2007). (in Russian)

3. Y.D. Sibikin, M.Y. Sibikin Diagnostika $i$ tehnicheskoe obsluzhivanie jelektroustanovok potrebitelej. Uchebnoe posobie [Diagnostics and maintenance of electric consumer units. Textbook] (Moscow, 2016). (in Russian)

4. A. B. Shelkov, Problemy upravlenija bezopasnost'ju slozhnyh sistem, materialy XXIII mezhdunarodnoj konferencii [Proceedings of XXIII international conference "Problems of safety management of complex systems"], 2016, (3). (in Russian)

5. GOST B23743 - 1988, GOST B20570 - 1988, GOST B20436 - 1988. Flight safety, reliability, controllability and repairability (Goscomizdat SSSR Publ., Moscow, 1988). (in Russian)

6. V.S. Viktorova, A.S. Stepanyants, Modelirovanie $i$ analiz kontroleprigodnosti bortovyh sistem samoletov [Modeling and analysis of controllability of on-board 
airplane systems] (Dependability Publ., 2007). (in Russian)

7. V.I. Dubrovin, V.A. Klimenko, Matematichni mashini i sistemi [Mathematical machines and models], 4 (2010). (in Ukraine)

8. A.A. Dubov, Occupational Safety in Industry, 3 (2003). (in Russian)

9. V.N. Ksendzov, G.A. Dyko, S.P. Murashko, Nadjozhnost' i kontrol' kachestva [Reliability and quality control], 10 (1988). (in Russian)

10. H.M. Chen, B. Vidakovic, N.D. Mavris, Technological Forecasting and Social Change, 1 (2004).

11. N.V. Lubkov, Institut problem upravlenija im. V.A. Trapeznikova RAN, XII Vserossijskoe soveshhanie po problemam upravlenija VSPU [Proceedings of XII AllRussian Conference on Control Issues at V.A. Trapeznikov Institute of Control Sciences of Russian Academy of Sciences] (Moscow, 2014). (in Russian)

12. N.R. Tarnurr, L.W. Stanton, Quantitative Forecasting Methods. The Duxbury Series in Statistics and Decision Sciences (Boston, PWS-KENT Publishing Company, 1989).

13. I.V. Lyubimov, S.A. Meshkov, Statisticheskie metody kontrolja kachestva $i$ nadezhnosti tehnicheskih sistem [Statistical methods of control of technical systems quality and reliability] (Baltic State Technical University Publ., Saint Petersburg, 2010). (in Russian)

14. N.S Loginova, S.V. Barsukov, S.V. Pakhomov, Model' prognozirovanija resursa tehnicheskogo objekta (sistemy) na osnovanii diagnostirovanija metodom minimal'nogo riska [Proceedings of VI Science and Practice Conference "Youth of the XXI century", Model of forecasting technical object resources based on minimum risk diagnosis] (Far East Federal University, Vladivostok, 2017). (in Russian)

15. Y.D. Sibikin, M.Y. Sibikin, Diagnostika $i$ tehnicheskoe obsluzhivanie jelektroustanovok potrebitelej. Uchebnoe posobie [Diagnostics and maintenance of electric consumer units. Textbook] (Moscow, 2016). (in Russian) 